\title{
How do you implement a Digital Environment to support a Training Group? \\ Comment organiser son environnement numérique pour soutenir le groupe en formation?
}

\section{Anne Ronchi}

\begin{abstract}
This case deals with an instructional designer (ID) working at a European university who has been asked to convert an existing on-campus program for working professionals to online delivery. This case took place over a period of several months and led to the development of an online training program. The program was designed to facilitate management of the individual training courses, while supporting exchanges between participants from a highly heterogenous audience. Interpersonal relationships that developed within the group remained a basic component of the training experience. The main challenges encountered by the instructional designer were the module-based courses that emphasized personalized learning, a lack of confidence in the Program Coordinator, and a lack of ICT knowledge by the design team in an institutional context unfavorable to the use of ICT. The courses offered by this university were mainly on-campus and the LMS was mainly used as a content repository.
\end{abstract}

Keywords: Europe, training group, LMS, blended learning, forum

\section{General Context}

\section{The stakeholders}

Henry: Pedagogical engineer

Martine: Coordinator of the training program 
Caroline: Director of the training program

Christine: Scientific collaborator, Continuing Education Service

Charles: IT developer, colleague of Henry

The University of the Lake proposes several learning management systems to help evolve its online courses and thus contribute to the ongoing improvement of quality in higher education. However, despite the institution providing access to various e-learning tools (LMS ${ }^{1}$, virtual campuses, virtual or digital working environments, etc.), faculty use the digital environments mainly to archive resources (e.g., document, course syllabi). Rare were those faculty who developed learning activities online. Henry had been working at the University of the Lake for six years and was recently hired to join the E-learning Support Team based on his successful experiences using the LMS for training programs. As part of of his new job, he was in charge of reporting on the technological and pedagogical (techno-pedagogical) needs of users linked to the various tools developed by the university's E-learning Support Team. This job was a pilot project to evaluate the effectiveness of integrating an ID into a team of computer programmers.

The courses offered by Lake University were mainly delivered on campus and the LMS was used primarily as a teaching resources repository. Blended courses were mainly of two types: 1) Teaching and Knowledge Acquisition or 2) Multimedia Resource-based Teaching (Burton et al., 2011). The latter type was quite common in the Continuing Education Department (CED), which encouraged Program Heads to integrate ICT in order to improve teaching and to make their programs more accessible. It was in this context that Henry was contacted by Christine. They had collaborated previously on a number of projects and found that they

\footnotetext{
${ }^{1}$ Learning Management Systems
} 
worked well together. Christine was an SME who worked for the CED and who spent a large amount of effort helping Program Committees imagine innovative teaching scenarios.

\section{The Training Program}

Christine wanted Henry to meet Martine who coordinated one of the CED's training programs. "Would you be available to work with Martine in assessing the usefulness of a platform for a module-based program?" During the conversation, Henry learned that Martine had had training on how to design an online course, something that should facilitate their collaboration. Shortly afterwards, a meeting was arranged.

At the first meeting, Henry was introduced to both Martine and Caroline, a faculty member at the University. As program head, $10 \%$ of Caroline's workload was devoted to the training program. However, she didn't have any experience using technology to support teaching and learning. Given the small amount of time Caroline had to devote to this project, the Continuing Education Department appointed Martine to work with her.

After the meeting, Caroline provided Henry with a broad outline of the program and then focused on more specifics. "Year after year, this program has proven to be successful. The next launch is almost ready. Participants take seven modules over the course of a full year and each module takes from three to four days to complete. The program targets working professionals." The development of on online version of this program was requested by the project committee to respond to both one-time training requests ${ }^{2}$ as well as requests for an undergraduate certificate ${ }^{3}$. Christine explained that the goal of this training was to enable working professionals to acquire both theoretical and practical capabilities but also "to build a community of practice including participants in training and faculty."

\footnotetext{
${ }^{2}$ A "credits statement" (equaling 5 credits, European Credit Transfer and Accumulation System, or ECTS) is issued once a participant has successfully completed one module.

${ }^{3}$ A certificate ( 15 credits) is issued once a participant has successfully completed 3 modules. A diploma (35 credits) is issued once a participant has successfully completed 7 modules.
} 
Henry asked Caroline about the teaching methods implemented in the program. He learned that the course design alternated between theory and participant experience by means of conferences, presentations, plenary discussions, and teamwork. Collaborative work mainly took place during in-class activities and between-class teamwork. Summative evaluation of students' performances with regard to the completion of the modules always included individually written assignments, which were highly standardized in form and content: "This standardization aims to train participants to complete work at the university level according to precise criteria," said Caroline. Before participants undertake these assignments, which involve reflection and writing, a considerable amount of reading is expected. Thus, each module supplies bibliographical resources to allow participants to work autonomously.

Henry received a copy of the program flyer. He took a moment to peruse it. Subsequently, Caroline told Henry how he could help them: "We need to provide the next cohort with an online space that is collaborative, easy to access, and easy to use. Technology literacy must be minimal because, as you know, things can get complicated whereas most of us, like our students, are not savvy in technology. Additionally, we'd like to get one module online ASAP."

\section{The training group}

Martine still hadn't said a word. Looking at her stony face, Henry guessed that something was not quite right. He decided to focus the discussion on taking the program online and said to Martine "Martine, will you be in charge of getting the LMS up and running?" After some hesitation and unenthusiastically, Martine answers: "I really don't know yet because I'm not an ICT expert. I took a course last year but I never got a chance to apply what I learned. And besides, during the course, when we used the LMS, it was really complicated... so I don't even know if I could do it again correctly." Henry was aware that the LMS had already been 
chosen but now he realized that Martine's participation was not a given. So he continued to include her in the discussion.

Martine told him that the decision to innovate in this program was made after a series of surveys had been conducted among target populations over the last three years. An initial needs analysis had revealed the importance of collaborative work in this kind of program in which working adults are enrolled. The participants, all working professionals, made two main recommendations to the program management. First, they advised that participants should be given digital access to all of the required course materials (administrative information, activities calendar, assignment deadlines, and course documents) and, second, they recommended that exchanges between participants and professors be independent of any time or space limits. A second survey, conducted internally, focused on describing participant career paths. It confirmed that the interpersonal relationships that were developed within a group remained a major component of the training experience.

\section{Meta-reflection on group training}

Henry was mainly worried about the welfare of the group because he knew how much the training group was a central element in the learning process, and also because "to construct or transform knowledge is a process which belongs ultimately to the learner alone [...], it can only be carried out through interactive confrontation with others [...]" (Bourgeois, 2004, p. 301). Social interaction positively influenced learning, a subject highlighted by the theory of socio-cognitive conflict (Doise \& Mugny, 1997). Consequently, for Henry, it was a matter of making sure that a strong link was maintained between the social and the cognitive, that is, within a training sequence or throughout an entire program, regardless of the type of teaching/learning scenario chosen or the proportion of activities that occurred face-to-face or online. For him it was important to do all he could to allow participants to meet and to discuss... (...but how?). 


\section{Module-building and group training}

After that eventful first meeting, Henry decided to immerse himself in the history of the program through the reports which with Martine had provided him. After reading all of the program assessment documents dealing with earlier iterations of the program, Henry noted that the strengths of the program were linked to the social dimensions of the training: the importance of the group and richness of the exchanges between peers and with their professors. The weaknesses were mainly linked to organizational and administrative dimensions, a lack of overall vision in the program, and the time used in training to address administrative questions. As for these latter elements, Henry was hardly surprised because, recurrently, participants who were enrolled in such module-based programs frequently complained about the organizational aspects of the training. Module-based training often resulted in an unclear vision of the program. To this complaint a second level of dissatisfaction was linked, that is, the little time available for informal exchanges among participants outside the classroom. Indeed, as enrollments increased, including greater numbers of people from various parts of the country, the quality and the frequency of interactions among participants had deteriorated, especially given their overloaded schedules with work and family and the resulting lack of availability.

\section{Meta-reflection on module-based training}

While thinking about the organizational aspects of the training, Henry noted that, in the past, most training was offered to groups of adults who completed various modules in the program. By reconsidering the engineering of the training based on this modular model, each module was composed of a stable core of participants who took the entire program together to which other participants came or went, having chosen other training courses. Such a model allowed for some degree of individualization based on a personalized pace of 
learning. In this case, for Henry, the learning pathways developed on the platform played the role of providing socio-affective support to the group based on "variable geometry"4, making it possible for participants to meet during face-to-face activities ${ }^{5}$ as well as online in order to accommodate feelings of frustration related to a lack of time for interaction. Again, for Henry, the wellfare of the group had to be a priority. For him, it was not contradictory to promote a modular model of training, which supported both the individualization of training and a group approach to training.

After reading the assessment reports and official transcripts of project committee meetings, in addition to discussions with Caroline and the people in charge of the modules, Henry started to get a good understanding of how the program was managed as well as the targeted teaching and learning innovations than they wished to introduce into this program.

Two weeks later, during another meeting, Henry shared his thinking with Caroline and Martine with regard to the objective of implementing the platform: "Based on the existing documentation and on our exchanges, I understand that your first aim, in using a platform, is to introduce methods that support collaborative training in your program." Caroline agreed: "Yes indeed, we want to reinforce and even go beyond face-to-face contact [1] between participants in order to preserve the feeling of belonging to a learning community." As Caroline saw it, the recent opening-up of the program, which made it possible for participants to choose their own training pathway, generated a lot of uncertainty with regard to how the program would be impacted. Martine added: "I also saw in other programs the extent to which the use of new technnologies can help in the organization of training, in particular questions about participant information-sharing, communications, and management." The fact that a platform had never been used before within the framework of a training program was anxiety-provoking for those in charge of moving the program online. Henry wanted to be

\footnotetext{
${ }^{4}$ Variable geometry refers to the variable composition of groups based on modules taken by participants.

${ }^{5}$ In a general sense and in this case, face-to-face activities refer to activities carried out in the classroom.
} 
reassuring so he decided to address what Martine did know. He confirmed that an online platform can simplify program management, in particular for handing in, marking and returning assignments as well as providing learners with official communications and collecting course satisfaction questionnaires.

However, despite his best efforts, Henry realized that Martine was still worried. This however encouraged him to openly express his own fears with regard to moving this program online. He realized she didn't have a clue how to go about organizing the program using the platform without participants getting lost in a maze of sub-menus. So Henry proposed that they meet at his office so that he could show her some exemplary online modules, which would illustrate various possibilities. Martine was visibly relieved and accepted his proposal with a wide smile.

\section{Stakeholder engagement}

A few days later, Martine met Henry in his office. He showed her various courses that he himself had designed using the same platform. He explained to her that all of these courses were built according to the ASPI model (Analysis, Support, Pilot the Innovation; PerayaJaccaz, 2004). Henry thought this model could help Martine formalize the various course components as well as the necessary design phases in moving the program online, while taking into account the expected management changes and teaching practices. Using the ASPI model and diagram (see Figure 1) as a starting point, Henry sketched out the process on a sheet which would make it possible to control the kind of change involved by engaging all of the stakeholders concerned.

Figure 1 A schematic drawing of the ASPI model as drawn by Henry 
Henry commented on the ASPI model above: "This figure allows us to understand the various components and phases that mustn't be neglected if one's intent is to modify, as it is in your case, faculty teaching practices when introducing a platform into their daily activities."

Martine: "So the only stakeholders here are faculty?"

Henry: "No, not only faculty, because other stakeholders are involved in this program intervention such as the program committee, the participants, and yourself as well. So you should make a list of all of the people who will play a role in the implementation of the program on the platform."

Martine: "OK, I get it. On the other hand, how do you deal with the "dimensions," on the right-hand side of your figure?"

Henry: "Well, this side allows you to consider how to take into account the dimensions in any training program. So, with regard to the pedagogical aspect, wouldn't you have to consider the main objectives? And as for instructional strategies, which one would you suggest to your colleagues? And you also have to consider how the participants will learn. I think it is really important to think about how the program will be implemented in the platform according to these various dimensions."

Martine: "Ah, I see... er, but in our case, there are elements which were already decided upfront, like the choice of the platform. It was an institutional decision."

Henry: "Yes, indeed, but that does not alter the approach in any way. You have elements which are arbitrary and with which you have to work. It is important to have that in mind when you explain to the various stakeholders involved in the migration of a program online. As in any project, there are critical events which require negotiation in order to improve the process."

Martine: "And the process has several phases, right? So where are we now?"

Henry: "Well, we both know the needs analysis has been done. You know what you want to do. We are now in the design phase in this project and we have to reflect on how to engage all of the stakeholders in this process, because it's a matter of integrating changes in daily practice. With everyone onboard, you will be able to decide how to organize the platform, how much space will be created, who will have access to this space, etc."

To illustrate what he was saying, Henry talked to Martine about the role of a teaching coordinator in an e-learning context.

\section{Meta-reflection about coordination}

Henry noted that the role of a teaching coordinator is often underestimated by the various stakeholders in a program. However, in a modular system, it is important that the 
management of the program designate a person to coordinate the training so as to have an overall picture of what is happening on a daily basis within the group. So the person who is assigned the role of teaching coordinator "is there to guarantee that the rules be followed, to maintain a social link between participants that neither the technique nor the machines can construct. All of the talk about personalizing training content is oblivious of the finetuning required in relationship to each student" (Réné-Boullier, 2002, p. xx). This role, according to Henry, was characterized by intense daily activities when the program was in startup mode and adjustments were being made to the program.

Henry encouraged Martine to continue thinking about the role of each stakeholder who would be helping to get the program online. Lastly, he reminded her that, to be able to control the innovation process, she should identify specific moments throughout the process when feedback should be collected in order to continuously assess the process. Henry realized that time was slipping between their fingers yet he had another meeting to attend. He told her that they'd get together in a few days to help her upload the modules onto the platform. But first, he asked Martine to confirm with Christine by email that she agreed to deal with putting the program online and to ensure its follow-up during the year. At the end of this meeting, Henry was hopeful that he'd sufficiently reassured Martine on her ability to organize the platform with her colleagues and furthermore, that she could do so autonomously. Without her, it will be very difficult to get this program online in time for the coming academic year.

\section{Implementation}

The following day, there was a pleasant surprise! Martine confirmed her interest in getting the program online: 'I met Henry yesterday. Thanks to him, I'll be able to create a website for the program on the platform and space for each of the modules." 
Relieved by her commitment to the project, Henry proposed meeting Martine the following week to start organizing the website. In order to allow each professor freedom to organize his or her own module, the project committee decided to create a space for each module. Over the course of two hours, they created seven spaces and they carried out a number of tests on the platform to make sure that Martine and her colleagues had administrator rights to manage these spaces and to upload activities they'd be using (forums, quizzes, surveys, assignments). In order to alleviate Martine's workload, Henry forwarded two documents to her: a Training Guide, which explained teaching fundamentals within the context of training via a digital platform. This guide was addressed to both faculty and participants. The second was a Technical Guide for professors to enable them to manage their own sites on the platform.

\section{Teaching principles}

By mutual agreement, Henry and Martine decided to re-examine the program after a month in order for Martine to have enough time to implement the main tasks involved in migrating the program onto the platform and to discuss this migration with her colleagues. During this time, they had a few email exchanges about pedagogical matters related to the integration of technology. So as to support interaction between participants, Henry suggested that Martine set up activities which would make it possible for participants to combine methods of training, alternating between individual work and teamwork, be they face-to-face or online, for each program module. This was intended to allow all of the participants to meet as often as possible, independently of the selected training module. With this clear intention in mind, Henry suggested that Martine implement, as a starting point, the concept of a learning community.

\section{Meta-reflection about learning communities}

Henry remembered that, according to Daele \& Brassard (2003, p. 3): “communities of 
learning are characterized by their institutional context and their relative perenniality since they are generally dependent on short-term activities. They are also based on learners' participation and their awareness of belonging to a community, which requires that faculty create the conditions which will support this participation." Henry knew that creating a learning community was never an explicit objective in and by itself; however, based on what Daele and Brassard were saying, learning activities, designed by IDs, often involve the creation of a learning community. The intent is that this community becomes a network of partners once the training is over. In order to move a group of learners towards a learning community, "The principle which underlies this process is that, in an innovative teaching/learning situation [...] the ongoing assessment of training by all of the actors concerned [...] largely contributes to making it evolve and to ensuring quality" (Daele \& Brassard, 2003, p.11). For Henry, these authors confirmed his understanding of the ASPI model. It was a question of engaging all of the stakeholders (professors, participants, coordinator, project managers, etc.) in ongoing reflection regarding program assessment.

While Martine had this online exchange with Henry, she asked him about getting funding for this project: "Could you help me work up an estimate on how much time it will take to get the program online?" Henry told her to write down all of the tasks which had to be carried out in order to organize the digital environment: creating the course on the platform, setting parameters for forum activities, structuring assignment and feedback mechanisms, onboarding (organizing the program's opening day with time for participants to become familiar with the platform), faculty training, participant enrollment, etc. Henry reminded her: "You'll have to jot down each and every activity that occurs every month to be able to estimate the number of hours required on an ongoing basis to pilot this project. Of course, during the launch period, you'll devote a little more time than you'd expect." After compiling the time allotments, 
Martine was able to estimate that taking this program online represented an additional workload of approximately 20 hours a month over the course of a year.

Three months passed. The seven sites, one for each module, were ready. Faculty had uploaded basic resources (course notes, reference documents, and complementary resources). Henry suggested that Martine mentor each professor individually in preparing their respective modules. As for Martine, she decided to put a standardized questionnaire online at the end of each module to collect participant feedback. Each module site had a discussion forum, the use of which was discussed with faculty. A contract between faculty and participants, establishing their rights and duties relating to the use of the platform, was published by the program committee. Its contents were negotiated with faculty in order to get their consent. The program's framework was now settled.

One month before the start of the new program, Henry suggested that Martine organize a final meeting bringing together the entire team in order to make sure that everyone understood what was expected them and to complete any final adjustments (such as login problems, technical difficulties in uploading documents, etc.). At this meeting, Martine reaffirmed her role as coordinator and pointed out how modularizing the program would affect the structure of the project team as discussed with Henry on several occasions.

Meta-reflection: Henry observed that continuing education had been offering programs using a modular-based approach for a long time, thus meeting the needs of participants to individualize their training. Moreover, he noted that the degree of heterogeneity in a group was often an important indicator of quality in training. Indeed, adult participants were unanimous on this: they found it important to be in groups with participants coming from different backgrounds. High heterogeneity allowed groups to experience multiple and complex realities in various professional settings. For Henry, social interaction multiplied 
the potential of a group in terms of training and thus activated socio-cognitive conflict and negotiation. Such meetings between peers require each participant to reconsider, and often reposition, their viewpoints.

The big day for launching the program and introducing the new digital environment had arrived. Henry asked Martine if she wanted him to attend but she declined, now sufficiently confident that all would go well. Together, they had addressed the most frequently-asked questions by participants at the beginning of training (post-training platform access time, enrollment difficulties, data confidentiality and, especially, grades, etc.) so Martine was not expecting anything out of the blue.

As it is often said: "No news is good news!" However, the following day, Henry called Martine to find out how things had gone on the first day. A cheerful voice answered him, saying:

"Hello, Henry... yes, everything went well; the participants encountered no login problems, and I was able to answer all of their questions. They wanted to know how long they'd have access to the platform. As we had discussed earlier, I told them that they'd have access to the platform up to six months after the end of the program. Phew! And then I was reassured to see that Caroline was familiar with the new environment. She praised the organization of the modules. That was nice! In any case, it is important for me that the director is involved. And if we were able to survive this first day, well it's thanks to you! I want to thank you for all your help! So long, Henry... we'll keep you informed on how things are going."

Henry was relieved; he believed he had done a good job.

\section{The evolution of teaching and learning practices}

Three months had passed since his phone conversation with Martine and, as they had agreed, a debrief with Martine had been organized. The new cohort, as well as the professors, were well initiated into their use of the platform. Martine confirmed that it had been a good idea to 
propose that participants learn to use the platform autonomously and to explain the adjacent teaching principles involved in setting up the program. In parallel, each professor benefited from individual training according to their knowledge and skills and based on any particular needs in organizing his or her module. Thanks to these decisions, Martine said she had not encountered any major design or development problems and all of the faculty had adopted the discussion forum, assignments dropbox and feedback components. In addition, it was a confirmation for Henry that taking these three activities online had made it possible for faculty to gradually understand and use the platform. Thus, in spite of some degree of hestitation felt at the beginning, the majority of faculty members engaged in organizing their modules (defining their respective profiles, adding photographs, uploading content to their modules, use of the discussion forum to transmit information or to answer questions). Henry was happy: "The faculty involved in this training have started to acquire new practices, a common language in relationship to the virtual platform; we are perhaps even seeing the beginnings of a new culture."

Thus, Henry and Martine hoped that, as Viens and Peraya (2004) said: "innovation will change the perceptions and practices of the actors and, in this sense, innovation becomes an arena for continuing education and is part of the culture of the actors" (quoted by Peraya \&Jaccaz, 2004). And indeed, by the end of a few weeks, new needs appeared. Faculty wanted to create online self-correcting quizzes to better prepare students for their exams.

Martine:

"Hello, Henry. We're designing a test in one of the modules. It's a twenty-question exam with short, open-ended answer questions. While working on the test, I realized that the system automatically corrects the answers of the participants. However, faculty wish to assess and mark participants' writing ability. Is there any way to simply compile participants' answers without the system marking them? I thought of just asking them to click on "upload a file" but, by doing that, you lose the chronometer function which limits the length of the test (set at 60 minutes). Do you know what to do?" 
Henry was delighted to see that Martine was now deeply engaged in the implementation of the program and the opportunities offered by the platform. Henry told her that one solution would be to set the test parameters to manual correction but, not being a specialist, he proposed that Martine talk to Charles who was an expert on the matter. Very quickly, Martine and Charles were in direct contact about this and other technical questions. Martine asked:

"Charles, another thing that really bugs me is... what do we do when the network goes offline while students are taking the test? Most of our students take their tests off campus, usually at home, and their wifi is not always reliable. I tried starting a test and then disconnecting, as if my computer had crashed. So the answers that I had saved were preserved but the chronometer stayed on, which is annoying. Any solution come to mind?"

Thus, over the next month, Henry and his colleagues from the Computer Science Department helped Martine get the tests up to speed. Martine's questions had mainly to do with how to choose the right questions and how to deal with the open-ended questions within the framework of an exam. Another difficulty related to login problems and allowing external users to access the platform. For reasons of security, managing external accounts was complex and involved a lot of red tape, the system often creating a barrier for program coordinators when integrating the digital environment into their practice. As a result of several snafus, Henry allowed Martine to meet with the computer science specialists about login rights and computer security.

For Henry, Martine's complete engagement with the program and the implementation of tests were strong indicators of ICT integration by the various faculty in this program. Moreover, feedback from both faculty and participants showed that the use of the activities (the forums, an interactive "rogue's gallery," online assignments, and other resources) made it possible for participants to exchange and to meet together, regardless of one's individual training pathway. Thus, the program coordinators found the answer to its concern about improving the training by getting the right information to the right people (administrative information, program and 
course support, documentation) without multiplying delivery channels. These various elements confirmed that the primary goal of its mission, namely, to provide an easy-to-use, collaborative activity-based site with minimal technical requirements to all of the participants involved in this training.

With this win behind them, Henry now proposed that Martine respond to the second part of Caroline's request which would allow them to ratify the change. Henry realized that promoting the administrative changes in managing learning allowed participants and faculty alike to adapt the platform and its various tools, but to integrate the use of the platform into actual teaching practices meant rethinking the instructional structure of the training modules. This was now Henry's next challenge!

\section{Discussion forums}

In order to encourage faculty to redesign the structure of a module in the program, Henry proposed adding online activities. In his view, this module would serve both as a test and a model demonstrating the possibilities of online activities.

\section{Meta-reflection about teaching posture}

Henry knew very well how difficult it is for faculty to change their teaching practices. He thought about various studies related to the role of new online instructors, in particular that of Sauvé and St-Pierre (2003, p. 1) who wrote: "Instructors have difficulty in adapting to individualized learning situations where their role is no longer a transmitter of knowledge, but rather a facilitator, a guide, an advisor." This new faculty role was part of an innovative approach and "an innovation can successfully be implemented only if all of the actors concerned can adapt it and concretely integrate it into their practices over time" (Denis, 2007). It was thus important for Henry to convince at least one or two professors to modify their module's structure.

Caroline presented the results of the assessment report on last year's program: 
"The design of the Integration module appears to have evolved from year to year but satisfies neither the team nor the participants fully. Basically, there is too much work for participants to do and for faculty to correct. I propose that we re-examine the structure of this module with Henry's help."

Martine: "We would like to put this module online, the objective being to support collaborative training within the learning community while making evaluation lighter."

The instructor in charge of the module: "Are you proposing I offer my module online? I don't agree. As instructor, I prefer to work face-to-face with my group."

Henry: "Not a problem. What we need to do is to provide particants with support between classes while they are working on their term projects by using offline activities."

Henry proposed to work with Martine and Caroline and to present a structured scenario to the team, which would allow the team to monitor participant knowledge acquisition.

\section{Meta-reflection on structuring}

For Henry, structuring was all about orchestrating intense interaction between individuals within a group since "it is the kind of interaction which occurs that determines the effects of learning that can be expected. Without intensity, there is no training!" (Dillenbourg, Poirier \& Carles, 2003, p. 23). The instructors and the design team were "stage directors" who, using the right technical support (platform, collaborative tools, etc.), a quality structure (including learning activities), as well as experienced actors (participants who were engaged in their own training), can succeed in making a catchy film, which fosters learning and the construction of a learning community.

Three working sessions were necessary for Henry, Martine, and Caroline to rebuild the structure for the Integration module, a six-month module to be delivered by Caroline. The storyboard developed was intended to help participants better understand the underlying mechanisms related to transferring new knowledge into professional practice. The approach was based on a literature review as well as on individual participant experiences in 
professional settings to be shared during the training. Henry insisted that Caroline and Martine imagine various learning activities (individual reading assignments, discussion groups on the forum, teams drafting transferral technique indicators), which aimed at activating conversation as a training mechanism.

Caroline: "I'm having a little trouble figuring out if the exchanges we expect to occur will indeed take place on the forum. How about, before we decide how to evaluate this activity, we wait to see what happens."

Henry: "Hmmmm. I think you've done a good job in restructuring the module: everything is quite clear... you've told participants what you expect from them... but it would be a pity to not tell them how they'll be evaluated from the get-go."

Caroline: "Yes, I agree. But, since we don't actually know if this is going to work, maybe we can just wait a few weeks and, based on what happens in the forum, then we can let them know how they'll be evaluated."

Henry: "OK, let's see what happens. But I strongly suggest that you carefully monitor the situation in the forum and that you intervene regularly to support the discussion, even though we had decided that one participant in the group be in charge of moderating the forum."

\section{Meta-reflection: about conversation as a model of training}

Henry was thinking about the conversational model developed by Laurillard (1995, cited by Henri, 2001) to organize forum work. Peer discussion and faculty feedback in knowledge construction are essential in training. Henry was truly convinced that good training must include exchanges, and conversation, because, without interaction, there is no learning. So Henry encouraged the instructors in charge of these modules to define objectives linked to communicating and collaborating. "It is while collaborators converse that they link up with one another; collaboration is built on conversation." (Henri, 2001, p. 61). From the socioconstructivist standpoint, meetings with others, debates, and controversies are all part of the module's structure aimed at provoking learning. The conversational model helps to formalize complex learning such as analysis and evaluation. 


\section{Feedback from the group in training}

As the program redesign is coming to an end, Henry proposed that Martine have the participants evaluate the feasibility of the program's structure and the digital environment. Henry was in the habit of using a questionnaire to evaluate online work based on three participant-perceived variables: usability, usefulness, and acceptability (Tricot, 2003). Henry wanted to know if the way the site was organized was learner friendly, including the various activities, the training support, use of the platform, etc.

On the last day of training, Martine distributed the questionnaire to the participants. A postfacto analysis of the answers showed that:

- Overall, the new hybrid scenario, alternating work in face-to-face and online modes was satisfactory, even if participants didn't always find it easy. An analysis of their answers also showed that the team's decision to only present one part of a module at a time prevented participants from having a comprehensive view of the approach. Some of them were under the impression that the module was being built on-the-fly.

- The module's evaluation methods were presented to participants somewhat "late in the day," so to speak. The fact that participants did not learn about the module's evaluation criteria at the same time they learned of the module's objectives initially destabilized them and created uncertainty as to what was expected from them in the discussion forums.

- The participants noted that the discussion about operationalizing their observation grid was constructive and that having it take place in asynchronous mode gave them time to reflect and so was relevant. They appreciated regular feedback from instructors in charge of the modules but they wished that they were more instructive in the forum. The idea of having participants moderate the forums was a flop, leaving a lot of questions without answers and allowing for discussion which was sometimes not very constructive. 
These results were discussed in the meeting with the design team. In Martine's mind, results confirmed that technology did indeed have its place in the program but she realized that better checks and balances should be implemented, in particular, by introducing a structure that accounted for and tracked improvements proposed by participants.

\section{Assessment and the future}

At the end of the program, at Henry's request, a final assessment meeting was organized with Martine and Caroline concerning Martine's initial lack of confidence and difficulties in coordinating the program.

\section{Martine's initial lack of confidence}

Henry reassured the coordinator in charge of organizing and taking the program online by putting Martine in charge. Her quick engagement and enthusiasm, evidenced by her developing tests in collaboration with some of the instructors, showed how much Martine, once she felt competent, had become a key resource in migrating the program online and the creation of an innovative, modular-based design structure.

\section{Difficulties the program coordinator faced dealing with finding human resources within} the institution.

During the first year, Martine regularly shared with Henry the problems she encountered in using the digital environment. Not always having the answer, Henry allowed Martine to contact the right people in the ICT field. Martine and Caroline thus developed "an E-learning address book" which enabled them to quickly find answers to their questions, whether they were technical or pedagogical.

For the team and for Henry, taking the program online allowed the following things to happen: centralizing the follow-up work (assignments and grades); locating all 
communications on the platform (general information and exchanges in the forums); making faculty and instructors autonomous in managing their modules (a separate space for each module); envisioning the program as a whole.

Today, the relative value of the platform is especially organizational in nature. However, from a pedagogical standpoint, groups in training evolve in a digital environment, the organization of which is facilitated by access to essential resources while respecting participant spatial and temporal limits. The online experimenting with a hybrid module allowed for the development of a different pedagogical structure, which only needed to be adapted to other modules.

Henry's mission thus came to an end. He was fully aware that getting a techno-pedagogial innovation underway took time, that there remained a ways to go, in particular, in faculty and instructor coordination, in order to involve them more in the approach and to help their creativity evolve in the way they used resources and activities available on the platform. Nevertheless, this experiment opened new prospects for the design team as a form of instructional engineering, which prioritized interaction between participants in a modularbased training format which promoted individualization. At the end of the project, Martine surprised even herself when she said: "Why can't we imagine that, one day, other modules will be offered in a hybrid format?" It could be a response to a recurring critique: getting everyone together in the same place at the same time is just too time-consuming for participants and their employers.

\section{References}

Bourgeois, E. (2004). Interactions sociales et performance cognitive. In Caspar P. et Carre P. (Ed.). Traité des sciences et des techniques de la formation. ( $2^{\mathrm{e}}$ édition) Paris : Dunod. 
Burton R. et al. (2011). Vers une typologie des dispositifs hybrides de formation en enseignement supérieur. Distances et savoirs, 1/2011 (Vol. 9), p. 69-96. https://archiveouverte.unige.ch/unige: 16586

Daele, A. \& Brassard, C. (2003). Communautés d'apprentissage dans l'enseignement supérieur : objectifs et conditions de développement. Paper presented at the $2^{\text {nd }}$ Guéret Conference, Les communautés virtuelles d'apprentissage, Guéret, June 2003.

Denis, B. (2007). Articuler théories et pratiques en technologie de l'éducation. In Charlier, B \& Peraya D. (Ed.). Transformation des regards sur la recherche en technologie de l'éducation, Bruxelles, De Boeck Supérieur, Perspectives en éducation et formation.

Dillenbourg, P., Poirier, C. \& Carles, L. (2003). Communautés virtuelles d'apprentissage: ejargon ou nouveau paradigme ? In A. Taurisson et A. Sentini. Pédagogies.Net. Montréal, Presses de l'Université du Québec.

Doise, W. \& Mugny, G. (1997). Psychologie sociale et développement cognitif. Paris. Armand Colin.

Henri, F. \& Lundgren-Cayrol, K. (2001). Apprentissage collaboratif à distance : pour comprendre et concevoir les environnements d'apprentissage virtuels. Sainte-Foy, QC: Presses de l'Université du Québec.

Peraya, D. \& Jaccaz, B. (2004). Analyser, Soutenir, et Piloter l'innovation : un modèle «ASPI ». In Actes du Colloque TICE 2004, Technologies de l'information et de la connaissance dans l'enseignement supérieur et l'industrie (pp. 283-289). Université de technologie. Compiègne (October19-21).

Sauvé, L. \& St-Pierre, C. (2003). Impact de la formation des agents de formation en milieu communautaire sur le développement de leur employabilité. Rapport intérimaire. Québec: SAVIE, décembre. 15 pages.

Réné-Boullier, L. (2002). Définir le rôle de la coordination pédagogique dans la formation à distance. In Actes du Colloque TICE 2002, Lyon, November 13-15, p. 23-28. Retreived from: http://docinsa.insa-lyon.fr/tice/2002/cs/cs011.html.

Tricot, R. et al. (2003). Utilité, utilisabilité, acceptabilité : interpréter les relations entre trois dimensions de l'évaluation des EIAH. In Actes de la Conférence Environnements informatiques pour l'Apprentissage Humain - Strasbourg 2003 (391-402). 